\title{
Effect of temperature and acidity of sulphuric acid on concrete properties
}

\author{
Mojtaba Mahmoodian ${ }^{1,}$ and Amir M. Alani ${ }^{2}$ \\ ${ }^{1}$ Lecturer, School of Engineering, RMIT, Australia \\ ${ }^{2}$ Professor, School of Computing and Engineering, University of West London, United Kingdom \\ *: corresponding author, Email: mojtaba.mahmoodian@rmit.edu.au
}

\section{ABSTRACT}

Concrete corrosion caused by sulphuric acid attack is a known phenomenon in sewer systems, resulting in significant economic losses and environmental problems. However, there is a scarcity of reported laboratory simulations and experimental work investigating the contributing factors controlling the corrosion. In this EPSRC (Engineering and Physical Sciences Research Council, UK) funded investigation the effect of temperature and the acidity of sulphuric acid solution on concrete specimens extracted from brand new concrete sewers has been investigated. In this investigation the concrete samples are submerged in three sulphuric acid solutions $(\mathrm{pH}=0.5,1$ and 2$)$ for 91 days under different temperatures $\left(10^{\circ} \mathrm{C}, 20^{\circ} \mathrm{C}\right.$ and $\left.30^{\circ} \mathrm{C}\right)$. Mass loss and compressive strength of the concrete specimens were tested and recorded at 7, 14, 28, 42, 56 and 91 days providing interesting data for visualising the changes taking place in the concrete samples (change in properties) during the time of immersion. The results revealed that samples overall mass increased at the early stages of the corrosion process. It also was observed that the overall mass of the samples decreased significantly at the later stages of the testing process with respect to the acidity of the solutions used.

Although the change in temperature did not have a significant effect on the compressive strength of the tested samples, rise in temperature however, had considerable effect on the mass loss of the concrete samples which were immersed in the most aggressive solution (i.e., $\mathrm{pH}=0.5$ and temperature $=30^{\circ} \mathrm{C}$ ) at 91 days. This research clearly demonstrated a high correlation between the acidity of the solution and the rate of corrosion with respect to time.

\section{KEYWORDS}

Concrete corrosion, sulphuric acid attack, corrosion rate, mass loss, compressive strength 


\section{Introduction}

The degradation of concrete sewer pipes by sulphuric acid attack is a substantial challenge globally, resulting in environmental impacts and economical losses of billions of dollars annually. Replacement and rehabilitation requirements related to the corrosion of concrete sewer pipes result in annual costs of $\$ 130$ million in the UK (Water UK, 2013a, 2013b) and $\$ 120$ million in Germany (Kaempfer and Berndt, 2013), which is a constantly growing threat for aging pipe sewer networks.

Concrete sewer pipe structural vulnerability is predominantly caused by sulphide corrosion which is dictated by the presence and high activity of sulphuric acid on the pipe wall and crown surfaces.

Generally the corrosion process goes through a three step chemical process: the sulphate contained in the wastewater transforms into sulphide (Figure 1), before the sulphide is released into the air in gas form, where the hydrogen sulphide is oxidised on moist surfaces into sulphuric acid (Parker, 1945a, 1945b; Vollertsen and Nielsen, 2008). The surface pH of new concrete pipe is generally between 11 and 13. Cement contains calcium hydroxide, which neutralises the acid. In active corrosion areas, the surface $\mathrm{pH}$ can drop to 1 or even lower and can cause a very strong acid attack. The corrosion rate of the sewer pipe wall is determined by the rate of sulphuric acid generation and the properties of the cementitious materials. As sulphides are formed and sulphuric acid is produced, hydration products in the hardened concrete paste (calcium silicate, calcium carbonate and calcium hydroxide) are converted to calcium sulphate, more commonly known by its mineral name, gypsum [ASCE 1989]. Gypsum provides little structural support, especially when wet. It is usually present as a pasty white mass on concrete surfaces above the water line. As the gypsum material is eroded, the concrete loses its binder and begins to spall, exposing new surfaces. This process will continue until the pipeline fails or corrective actions are taken.

To understand the process of concrete corrosion and its rate, accelerated experiments with the use of sulphuric acid have been undertaken. Jahani et al (2001a\&b) exposed concrete samples to a sulphuric acid solution of $2-3 \mathrm{pH}$ over 72 days, where a corrosion rate of $0.82 \mathrm{~mm} / \mathrm{year}$ was observed. In a research by De Belie et al (2004) subsequent steps of immersion and drying, combined with mechanical abrasion, were applied to simulate events occurring in sewer systems. To simulate sulphuric acid attack, three cylinders of each concrete type were subjected to 10 attack cycles consisting of an alternated immersion in a $0.5 \%$ sulphuric acid 
solution (initial pH 0.9-1.0), drying by air and brushing. They also assessed the effect of W/C

82 ratio and the cement type on the corrosion rate. Gutierrez-Padilla et al (2009) estimated corrosion rates of $2.19,0.76$ and $0.18 \mathrm{~mm} /$ year for concrete samples exposed for 64 days in $0.5 \%, 0.2 \%$ and $0.05 \%$ sulphuric acid solution. Most research on the resistance of concrete to sulphuric acid attack has considered the effectiveness of the change in concrete mix design on concrete resistivity (Bassuoni and Nehdi, 2007; Hewayde et al, 2007; Nnadi and LizarazoMarriaga, 2013). However, more rarely investigated is the effect of the main practical environmental factor (i.e., temperature) on chemical corrosion.

The current study is a part of an extensive project supported by the Engineering and Physical Sciences Research Council (EPSRC) on the assessment of the remaining life of the cementitious sewer pipes in the UK. The research involves both lab and field experiments and investigates the parameters affecting sulphide corrosion of concrete sewers and consequently the structural reliability of the sewers. In this paper the results of the lab experiments are presented. The aim is to assess the establishment of the corrosion process on concrete samples exposed to sulphuric acid solution with different temperature regimes and different levels of acidity, which has not been investigated in depth previously.

The deterioration of concrete could be evaluated by percentage of mass loss with respect to time (time of exposure to acid solution) under laboratory conditions. This also could be extended to the variations in the compressive strength of the samples tested within the context of the mechanical property of the concrete.

The output of this study can be helpful for research in the area of modelling the deterioration of concrete sewers as well as service life prediction and reliability analysis of these types of corrosion affected pipelines (Mahmoodian and Alani, 2013; Yuan et al, 2013; Alani et al, 2014; Mahmoodian and Alani, 2014).

\section{Experimental work}

To consider the effect of temperature and level of acidity on concrete properties, a test plan is proposed in this study based on the immersion of concrete samples into sulphuric acid and measurement of the mass and strength loss of the specimens. The concrete samples are submerged in three sulphuric acid solutions $(\mathrm{pH}=0.5,1$ and 2$)$ for 91 days under $10^{\circ} \mathrm{C}, 20^{\circ} \mathrm{C}$ and $30^{\circ} \mathrm{C}$ temperature regimes. Therefore, a total of nine series of test specimens will be investigated (three temperature levels and three $\mathrm{pH}$ levels). Mass loss and compressive 
strength of the concrete specimens are measured after 7, 14, 28, 42, 56 and 91 days of immersion.

\subsection{Sample preparation}

113 properties of concrete pipes such as permeability, porosity and water absorption (Binici et al

114 2012). While in the most of the laboratory based experimental investigations the concrete 115 specimens are fabricated in-situ (in the laboratory) (Jahani et al 2001a\&b, Hewayde et al, 1162007 and Nnadi and Lizarazo-Marriaga, 2013), in order to simulate the real field condition, in 117 this research however, concrete cubes were cut from a brand new sewer pipe. This approach 118 ascertains the high quality as well as the uniformity (in size) and homogeneity (consistency of 119 the mix) of the samples used in this research.

120 A brand new non-reinforced concrete pipe produced by a concrete pipe manufacturer in the 121 UK was selected for sample preparation. The diameter and the length of the pipe were $0.7 \mathrm{~m}$ 122 and $2.5 \mathrm{~m}$ respectively and the manufacturer did not declare the concrete mix design due to 123 commercial sensitivity of the design mix. It is important to point out that the aim of this investigation was not to investigate concrete design mixes and/or finding the optimum concrete design mix resistant against acid attack. The main aim of this research was to investigate the effect of environmental conditions (temperature and acidity) on the mechanical properties of concrete sewer pipes, therefore as long as the samples used were of similar dimensions and ingredients, the concrete mix design should not impose or be considered as a technical challenge or shortfall. Nevertheless, the samples used for this research were all in compliance with the sewer pipe design standard and code of practice in the UK.

132 Considering three samples for testing at six different immersion times for nine series of solution conditions, a total number of 162 cubic specimens were cut from the brand new circular concrete sewer pipe to be used in the experiments. In order to ascertain the compressive strength of the concrete before immersion, six extra samples were also prepared. Each cube had approximate dimensions of $100 \times 100 \times 100 \mathrm{~mm}$ and was cut with a diamond-blade rotating saw. However, as the process of cutting a circular pipe is very challenging and labour consuming, a tolerance of $10 \%$ for each side measurement of the cube was allowed (Figure 2).

\subsection{Sulphuric acid baths}


143 Nine containers made of acid resistant PVC with dimensions of 700x700x400mm and a

144 volume of $196 \mathrm{~L}$ were filled to two-thirds of their height with sulphuric acid solutions (Figure

145 3). All sulphuric acid solutions were prepared by mixing de-ionized water with

146 predetermined amounts of condensed sulphuric acid to gain the desired $\mathrm{pH}$ level. The

147 temperature and $\mathrm{pH}$ levels of the sulphuric acid solutions were monitored daily using a digital

148 thermometer with accuracy of \pm 0.1 and a digital $\mathrm{pH}$ meter with \pm 0.05 accuracy. Figures 4 and

1495 show examples of $\mathrm{pH}$ and temperature monitoring records for sulphuric acid baths with $150 \mathrm{pH}=0.5$ and temperature $=10,20$ and $30^{\circ} \mathrm{C}$, respectively. Concentrated sulphuric acid was 151 added periodically to the solutions to maintain the $\mathrm{pH}$ level within an acceptable range of the designated concentration.

As previously mentioned, 18 concrete specimens were immersed in each of the nine sulphuric acid tanks containing 130L of solution. Therefore, a total of 162 test specimens were oven dried at $105^{\circ} \mathrm{C}$ until they reached constant mass, weighed using a digital scale (accuracy of $\pm 0.01 \mathrm{~g})$ and then immersed into the sulphuric acid tanks with $\mathrm{pH}=0.5,1$ and 2 and three different temperature levels (i.e., $10^{\circ} \mathrm{C}, 20^{\circ} \mathrm{C}$ and $30^{\circ} \mathrm{C}$ ).

Measurements were performed at 7, 14, 28, 42, 56 and 91 days of sulphuric acid immersion; at each date three specimens were removed from each tank, rinsed and carefully brushed and oven dried at $105^{\circ} \mathrm{C}$ until constant mass was achieved. The specimens were subsequently cooled at room temperature, weighed and prepared for compressive strength testing.

165 The percentage of mass loss at each date was calculated according to the following equation: where $M_{1}$ is the mass of the specimen before immersion and $M_{2}$ is the mass of the specimen after immersion. Mass loss is commonly used to evaluate the deterioration of concrete under acid attack (Ehrich et al, 1999; Hewayde et al, 2007; Nnadi and Lizarazo-Marriaga, 2013).

170 Compressive strength tests were also performed at 7, 14, 28, 42, 56 and 91 days using a hydraulic machine with a loading rate of $14.4 \mathrm{MPa} / \mathrm{min}$ as per ASTM C39 guidelines. Three identical specimens from each series were tested at each date and the average value is reported. The reduction in compressive strength of the corroded specimens was calculated as follows (ASTM C267): 
178 where $f_{o}$ is compressive strength of control samples (before immersion) and $f_{t}$ is compressive strength after $t$ days of immersion in sulphuric acid.

180

181

182

183

184

185

186

187

188

189

190

191

192

193

194

195

196

197

198

199

200

201

202

203

204

205

206

207

208

209

210

211

212

213

\section{Results and discussion}

\subsection{Effect on mass loss}

Figure 6 shows the evolution of the mass loss of the specimens for each temperature level. In the early stages, mass gain occurred for all the specimens. This mass increase had been found in other research undertaken by Nnadi and Lizarazo-Marriaga (2013). They describe this reaction as producing a decrease in density and an increase in volume. If the increase in volume is greater than the loss of density, mass increase could occur. However, the authors of the current research believe that the mass gain during the early ages can be explained by the ability of concrete to absorb the acid via micro-pores and the formation of gypsum that occurs under the concrete surface. The corrosion products under the surface layer of each specimen are not loose enough to be easily washed away, resulting in mass gain. As acid reaction continues, corrosion products at the surface become greater than what has been formed in the micro pores; they are loose enough to be washed away and so subsequent mass loss occurs. In Figure 7, degradation of the concrete samples with time is visually investigated. The production of a white coloured material on the concrete surface at the early ages of immersion is evidence of the creation of gypsum, but this corrosion product is not large enough or loose enough to be washed away from the surface of the specimen. At later stages, for example after 91 days (Figure $7 \mathrm{~g}$ ), the progress of corrosion has resulted in relatively substantial gypsum production; as this is washed away significant mass loss occurs.

It can also be observed that, within the first 56 days, the rate of mass change is not affected by temperature. However for 91 day specimens in $\mathrm{pH}=0.5$, much greater mass loss is observed at higher temperature levels. This result, together with a visual inspection of the samples, reveals that, during the acid degradation process, the temperature of the sulphuric acid solution accelerates the mass loss by loosening the bonds between aggregates and cement paste. The main focus of large proportion of the available literature within the field has been on the effect of temperature on the bacterial degradation of concrete (Alexander et al 2013, Alani et al 2014 and House and Weiss 2014) and to the best of the authors' knowledge there are rather limited investigation results available on temperature effect on 
214 chemical acid attack progression in concrete specimens (Okochi et al. 2000 and Zhang et al.

215 2012). However, in practice concrete can potentially degrade differently in various climate 216 and temperature conditions regardless of presence of bacteria. It also should be appreciated

217 that the investigation of bacterial degradation of concrete, and in particular in cementitious

218 sewer pipe scenarios, is a major research and development field which requires specialist and

219 dedicated infrastructure and equipment as well as expertise.

220 The results of mass loss measurements presented in Figure 6 also clearly show that the trend 221 of mass loss for the most acidic solutions (i.e., $\mathrm{pH}=0.5$ ) is considerably higher than for the other two pH levels.

Figure 8 shows the change in compressive strength of concrete samples in each condition within time of immersion. The results confirm that the effect of temperature change on corrosion progress is negligible. However, the trend in the graphs demonstrates that the more acidic the solution, the greater the reduction in compressive strength. This is similar to the mass loss and can be also illustrated in the form of Figure 9. In this figure the mass loss and compressive strength after 91 days immersion in the three temperature conditions are illustrated. Both bar charts show the maximum effect caused by the most acidic solution (i.e., $\mathrm{pH}=0.5)$ on the concrete properties.

\subsection{Relationship between mass loss and compressive strength degradation}

238 The relationship between the mass loss experienced by all concrete specimens subjected to sulphuric acid and the reduction in their compressive strength is shown in Figure 10. It is observed that compressive strength declined as mass loss increased. This directly proportional relationship can be attributed to the fact that immersing concrete specimens in sulphuric acid results in loss of cement paste and structural integrity, weakening of the concrete matrix and a reduction in the specimen's diameter.

244 The graph in the figure is divided into four quadrants, with their point of intersection represented by the average compressive strength and mass loss of all the samples. It is clear from the figure that all the points for solutions with $\mathrm{pH}=0.5$ are located in the upper right quadrant, which have above average values for both mass loss and loss in compressive strength. The mass loss and loss in compressive strength at the other two $\mathrm{pH}$ levels (i.e., $\mathrm{pH}=1$ and $\mathrm{pH}=2$ ) are considerably lower. This confirms the fact that the effect of acidity level 
on concrete resistance does not follow a linear correlation and, as the $\mathrm{pH}$ of the acid reduces, the chemical reaction occurs progressively.

252

253

254

255

256

257

258

259

260

261

262

263

264

265

266

267

268

269

270

271

272

273

274

275

276

277

278

279

280

281

282

283

\section{Conclusion}

This study investigated the effect of temperature and acidity level on the resistance of concrete to chemical sulphuric acid attack. Mass loss and loss in compressive strength of concrete samples extracted from a brand new concrete pipe were checked after immersion in solutions of three $\mathrm{pH}$ levels $(\mathrm{pH}=0.5,1$ and 2$)$ and kept at three temperature levels $\left(\mathrm{T}=10^{\circ} \mathrm{C}\right.$, $20^{\circ} \mathrm{C}$ and $30^{\circ} \mathrm{C}$ ) for 91 days.

It was noted that, at the very early stage of the corrosion process, concrete mass increased for all conditions. For the higher temperature acid solutions, greater mass loss was observed in the long term.

Overall, in the acid degradation process, the temperature of the sulphuric acid solution accelerates the mass loss by loosening the bonds between aggregates and cement paste. This results in aggregate loss and eventually higher depth of corrosion. This finding confirms the mechanical effect of temperature on the degradation process in concrete sewers.

It was also found in this study that the level of acidity of acid solutions progressively affects the concrete properties (i.e., mass loss and compressive strength).

It needs to be noted that mass loss and compressive strength were used in this research as major and common indicators for change in durability and mechanical properties of concrete subject to acid attack. However, other measures such as water absorptivity and permeability as well as chemical and/or microstructural analysis also can be used in future studies to further investigate concrete behaviour in an acidic environment.

\section{Acknowledgements}

The authors' sincere thanks go to the EPSRC grant, EP/I032150/1 - 'Assessing Current State of Buried Sewer Systems and Their Remaining Safe Life' - which made materialisation of the above work possible. Thanks also extend to the British Precast Concrete Federation (BPCF) for its constructive comments and supportive role in providing the required concrete pipe (a real life size sewer pipe) for sampling purposes. The authors wish also to thank Dr. Alan Staple from the Chemical Laboratory at the University of Greenwich for his supportive comments and assistance, in addition to the Department of Civil Engineering concrete 
technology laboratory staff at the University of Greenwich (where the authors were based for the duration of this research) for their continuous support in terms of facilities, infrastructure and technical assistance. Finally, the authors would like to thank postgraduate student, Mr. Upul Chandrasekara for his participation in the laboratory work

\section{References}

Alani, A., Faramarzi, A., Mahmoodian, M. and Tee K. F., (2014), Prediction of sulphide build-up in filled sewer pipes, Journal of Environmental Technology, Aug;35(13-16):1721-8 Alexander, M., Bertron, A. and De Belie, N., (2013) Performance of cement-based materials in aggressive aqueous environments, State-of-the-Art Report, RILEM TC 211 - PAE Bassuoni, M.T. and Nehdi, M.L., (2007), Resistance of self-consolidating concrete to sulfuric acid attack with consecutive pH reduction, Cement and Concrete Research 37, 1070-1084 Binici, H., Durgun, M.Y., Rızaoğlu, T. and Koluçolak, M., (2012), Investigation of durability properties of concrete pipes incorporating blast furnace slag and ground basaltic pumice as fine aggregates, Scientia Iranica, Volume 19, Issue 3, June, Pages 366-372 CPAA (2014), Concrete Pipe Facts, the Concrete Pipe Association of Australasia De Beliea, N., Monteny, J., Beeldens, A., Vincke, E., Van Gemert, D. and Verstraete, W., (2004) Experimental research and prediction of the effect of chemical and biogenic sulfuric acid on different types of commercially produced concrete sewer pipes, Cement and Concrete Research 34, 2223-2236

Ehrich, S., Helard, L., Letourneux, R., Willocq, J. and Bock, E., (1999) Biogenic and chemical sulfuric acid corrosion of mortars, Journal of Materials in Civil Engineering, Vol. 11, No. 4, November

Gutierrez-Padilla, M.G.D., Bielefeldt, A., Ovtchinnikov, S., Pellegrino, J. and Silverstein, J. (2009), Simple scanner-based image analysis for corrosion testing: Concrete application, J. Materials Processing Technology, 209, 51-57.

Hewayde, e., Nehdi, M., Allouche, E. and Nakhla, G., (2007), Effect of Mixture Design Parameters and Wetting-Drying Cycles on Resistance of Concrete to Sulfuric Acid Attack, Journal of Materials in Civil Engineering, Vol. 19, No. 2, February 1.

House, M. W. and Weiss , W. J., (2014), Review of Microbially Induced Corrosion and Comments on Needs Related to Testing Procedures, 4th International Conference on the Durability of Concrete Structures 24-26 July 2014 Purdue University, West Lafayette, IN, USA 
321 Jahani, F., Devinny, J., Mansfeld, F., Rosen, G., Sun, Z. and Wang, C., (2001a),

322 Investigations of sulfuric acid corrosion of concrete. I: Modeling and chemical observations,

323 Journal of Environmental Engineering-ASCE 127(7): 572-579.

324 Jahani, F., Devinny, J., Mansfeld, F., Rosen, G., Sun, Z. and Wang, C., (2001b), 325 Investigations of sulfuric acid corrosion of concrete. II: Electrochemical and visual 326 observations, Journal of Environmental Engineering-ASCE 127(7): 580-584.

327 Kaempfer, W. and Berndt, M., (1998), Polymer modified mortar with high resistance to acid 328 corrosion by biogenic sulphuric acid, Proceedings of the IX ICPIC Congress, Bologna, Italy, 329 pp 681-687.

330 Koch, G.H., Brongers, M.P.H., Thompson, N.G., Virmani, Y.P. and Payer, J.H, (2002), 331 Corrosion Costs and Preventive Strategies in the United States, NACE International

332 Mahmoodian, M. and Alani, A., (2013), Multi failure mode assessment of buried concrete 333 pipes subjected to time dependent deterioration using system reliability analysis, Journal of 334 failure analysis and prevention: Volume 13, Issue 5, Page 634-642

335 Mahmoodian, M. and Alani, A., (2014), Modelling deterioration in concrete pipes as a 336 stochastic Gamma process for time dependent reliability analysis, Journal of pipeline systems 337 engineering and practice, ASCE, Volume 5, Issue 1, 04013008

338 Mori, T., M. Koga, et al. (1991), Microbial Corrosion of Concrete Sewer Pipes, $\mathrm{H}_{2} \mathrm{~S}$ 339 Production from Sediments and Determination of Corrosion Rate, Water Science and 340 Technology 23(7-9): 1275-1282.

341 Mori, T., T. Nonaka, et al. (1992), Interactions of Nutrients, Moisture and Ph on Microbial 342 Corrosion of Concrete Sewer Pipes, Water Research 26(1): 29-37.

343 Nnadi, E. O. and Lizarazo-Marriaga, J., (2013), Acid Corrosion of Plain and Reinforced 344 Concrete Sewage Systems, Journal of Materials in Civil Engineering, ASCE, Vol. 25, No. 9, 345 September 1

346 Okochi, H., Kameda, H., Hasegawa, S., Saito, N., Kubota, K. and Igawa, M, (2000),

347 Deterioration of concrete structures by acid deposition- an assessment of the role of rainwater 348 on deterioration by laboratory and field exposure experiments using mortar 349 specimens, Atmospheric Environment, Volume 34, Number 18, 1 December, pp. 2937$350 \quad 2945(9)$

351 Parker, C. D. (1945a), The Corrosion of Concrete .1. The Isolation of a Species of Bacterium 352 Associated with the Corrosion of Concrete Exposed to Atmospheres Containing Hydrogen 353 Sulphide, Australian Journal of Experimental Biology and Medical Science 23(2): 81-90. 
354 Parker, C. D. (1945b), The Corrosion of Concrete .2. The Function of Thiobacillus355 Concretivorus (Nov-Spec) in the Corrosion of Concrete Exposed to Atmospheres Containing

356 Hydrogen Sulphide, Australian Journal of Experimental Biology and Medical Science 23(2): 357 91-98.

358 Vollertsen, J., A. H. Nielsen, Jensen, H. S., Wium-Andersen, T. and Jacobsen, T. H., (2008), 359 Corrosion of concrete sewers - The kinetics of hydrogen sulfide oxidation, Science of the 360 Total Environment 394(1): 162-170.

361 Water UK, (2013a), Expenditure variables - Wastewater

362 Water UK, (2013b), Industry Data Share 2013

363 Yuan, H., Dangla, P., Chatellier, P. and Chaussadent, T., (2013), Degradation modelling of 364 concrete submitted to sulfuric acid attack, Cement and Concrete Research 53, 267-277

365 Zhang, Y., Fan, Y. and Li, H., (2012), Influence of Simulated Acid Rain Corrosion on the 366 Uniaxial Tensile Mechanical Properties of Concrete, International Journal of Corrosion 367 Volume 2012

368

369

370

371

372

373

374

375

376

377

378

379

380

381

382

383

384

385

386 


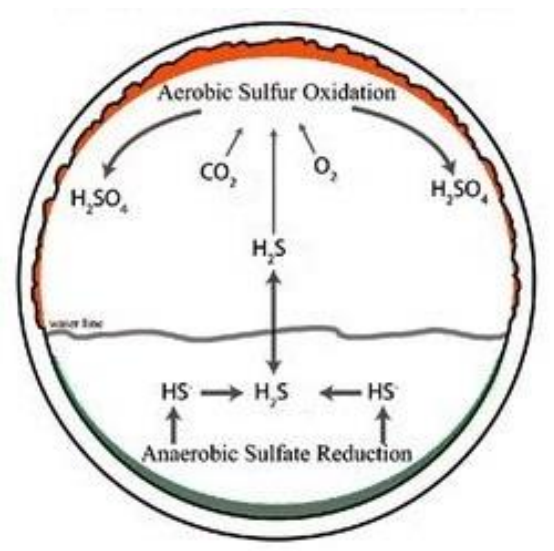

Figure 1. corrosion process in concrete sewers, [Water Stinks, Understanding sewer condition, http://waterstink.com/tag/concrete-sewers/]
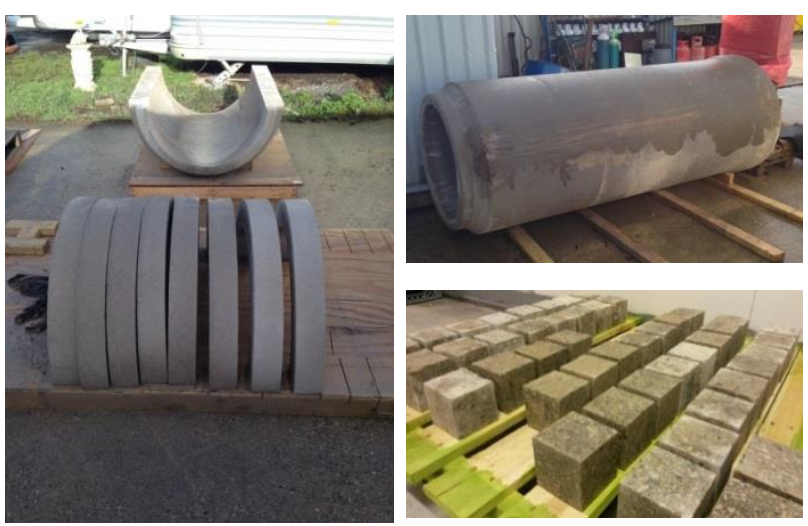

Figure 2. cube specimens extracted from a brand new concrete pipe

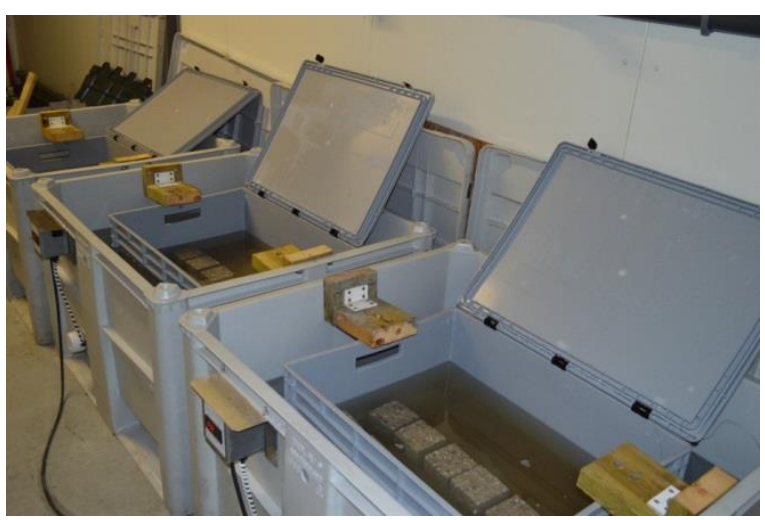

Figure 3. Sulphuric acid bath with controlled $\mathrm{pH}$ value and temperature 


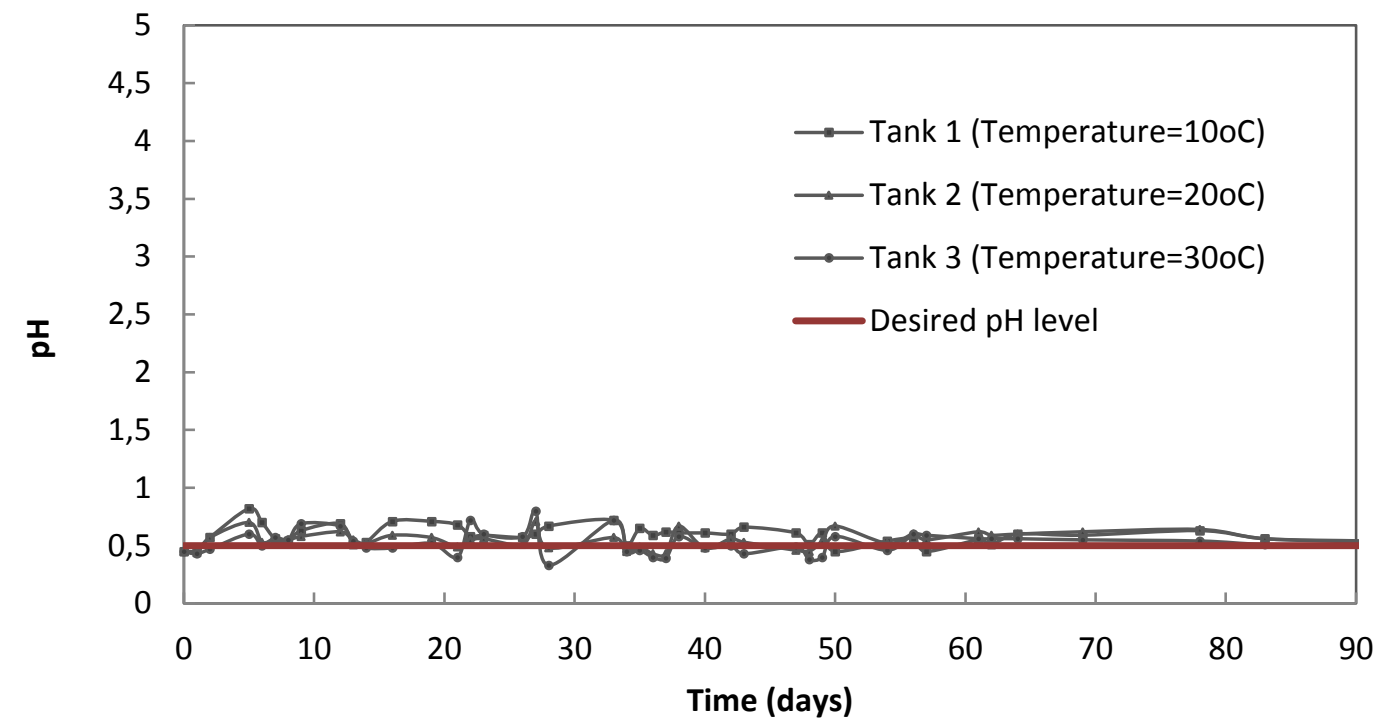

427

428 Figure 4.pH monitoring records for the three temperature regimes during period of immersion 429

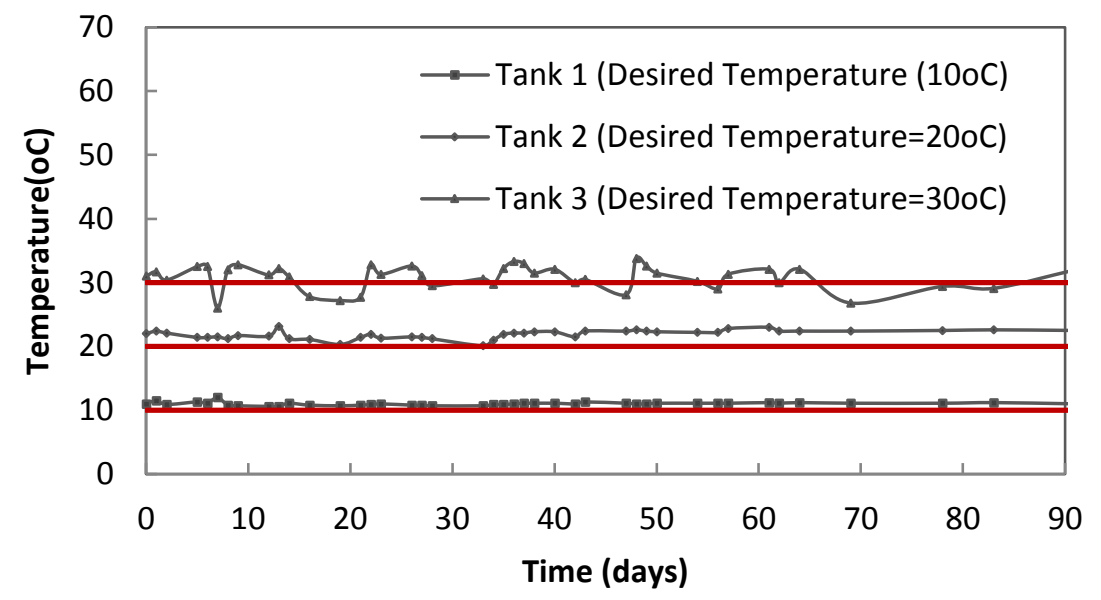

430

431 Figure 5.Temperature monitoring records for sulphuric acid solutions with $\mathrm{pH}=0.5$ during 432 period of immersion in the three temperature regimes 


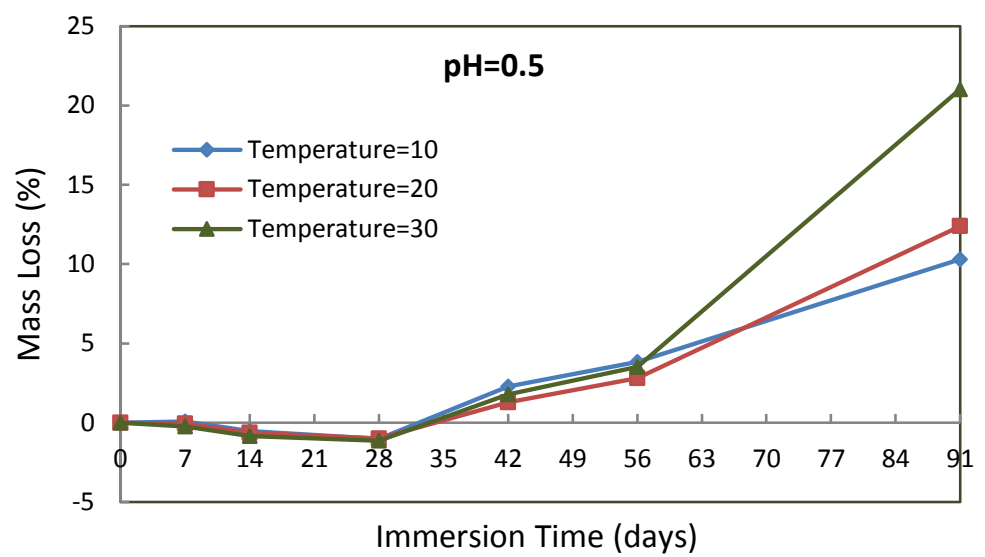

435

436

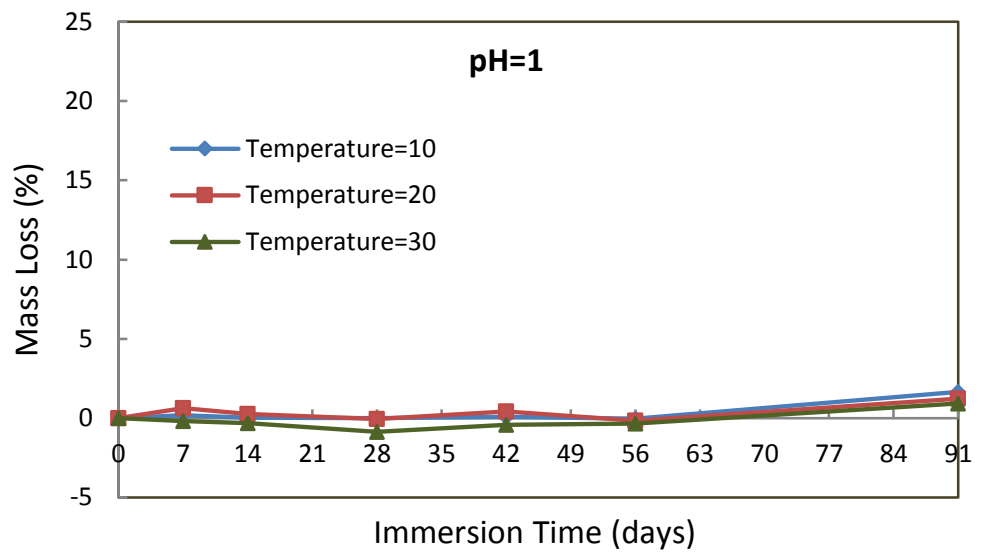

437

438

439

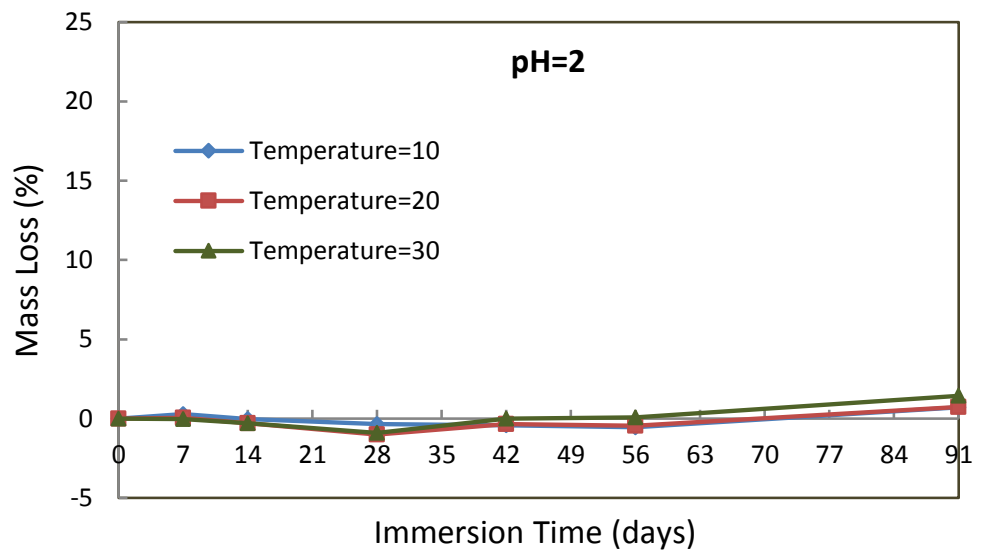

440

441 Figure 6. Mass loss of the specimens in three different sulphuric acid solutions and three temperature regimes 
445

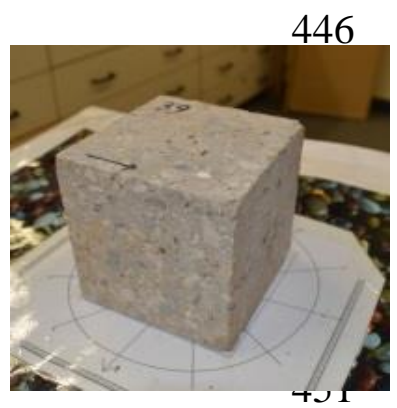

(a)

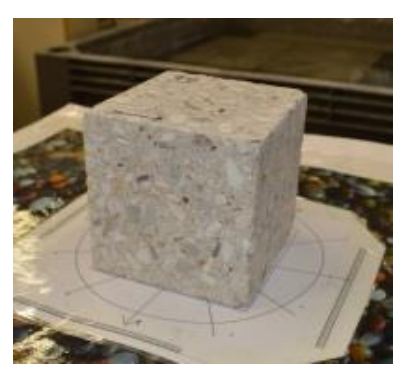

(b)

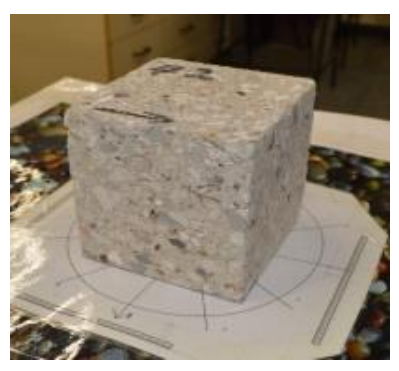

(c)

453

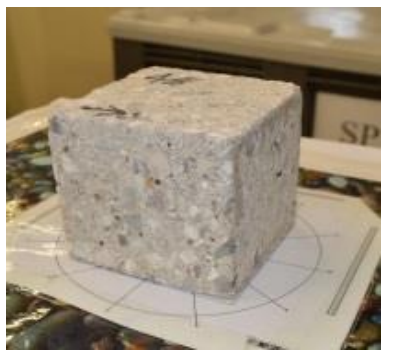

(d)

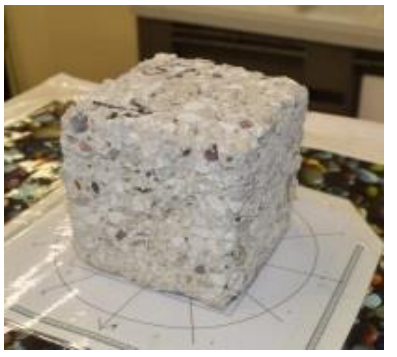

(e)

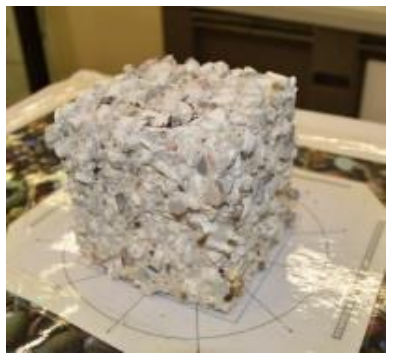

(f)

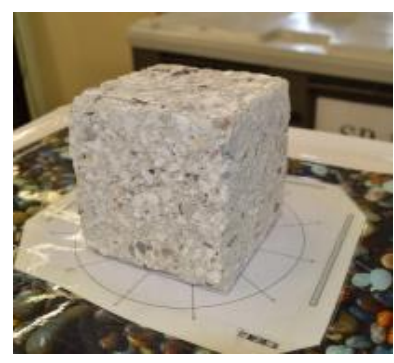

(g)

455 Figure 7: (a) control specimen before immersion, (b) to (g) specimens after 7, 14, 28, 42, 56 456 and 91 days immersion in sulphuric acid, respectively.

457

458 


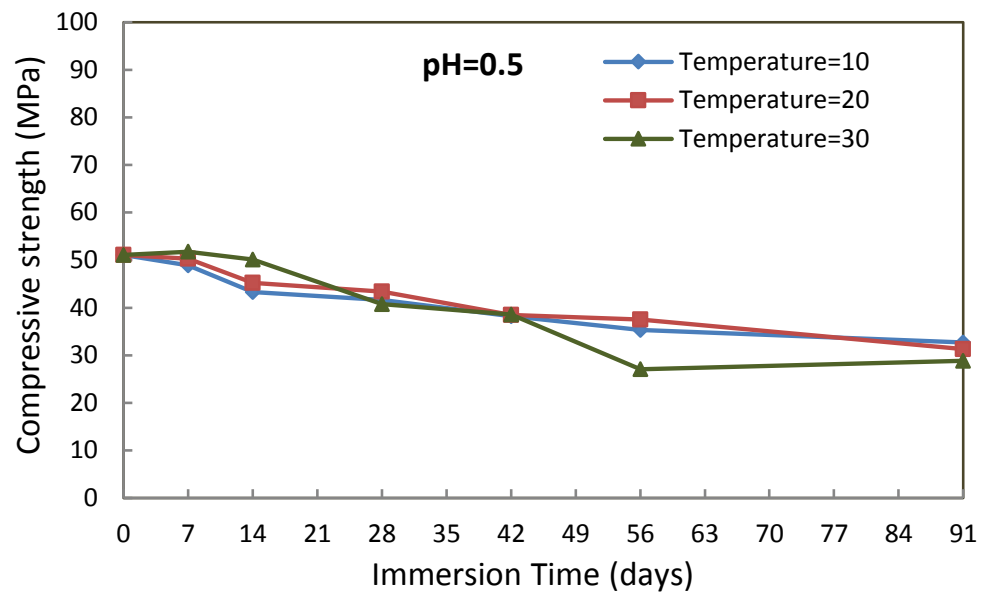

459

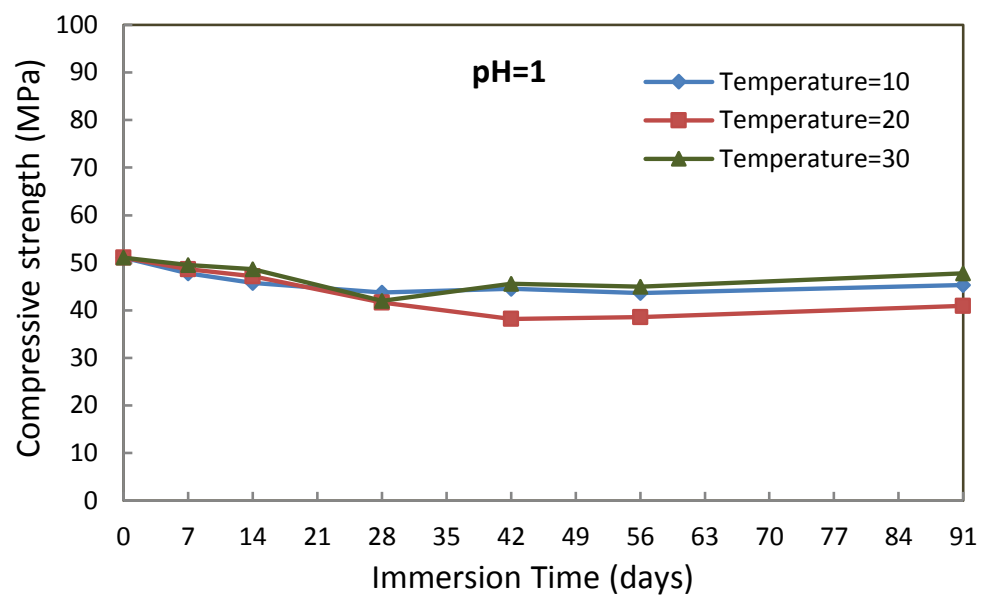

460

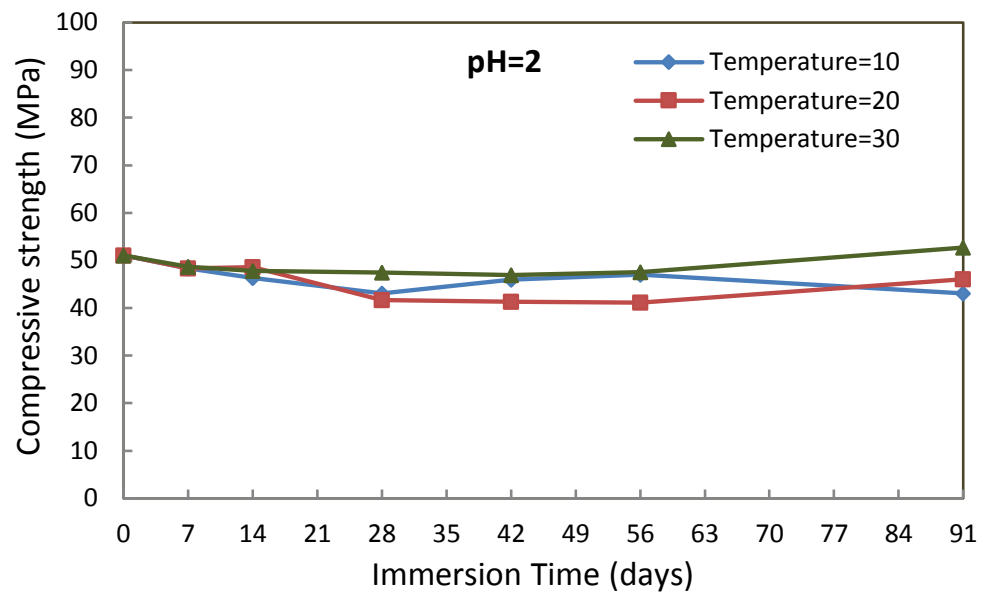

462 Figure 8. Compressive strength of the specimens in three different sulphuric acid solutions and three temperature regimes. 


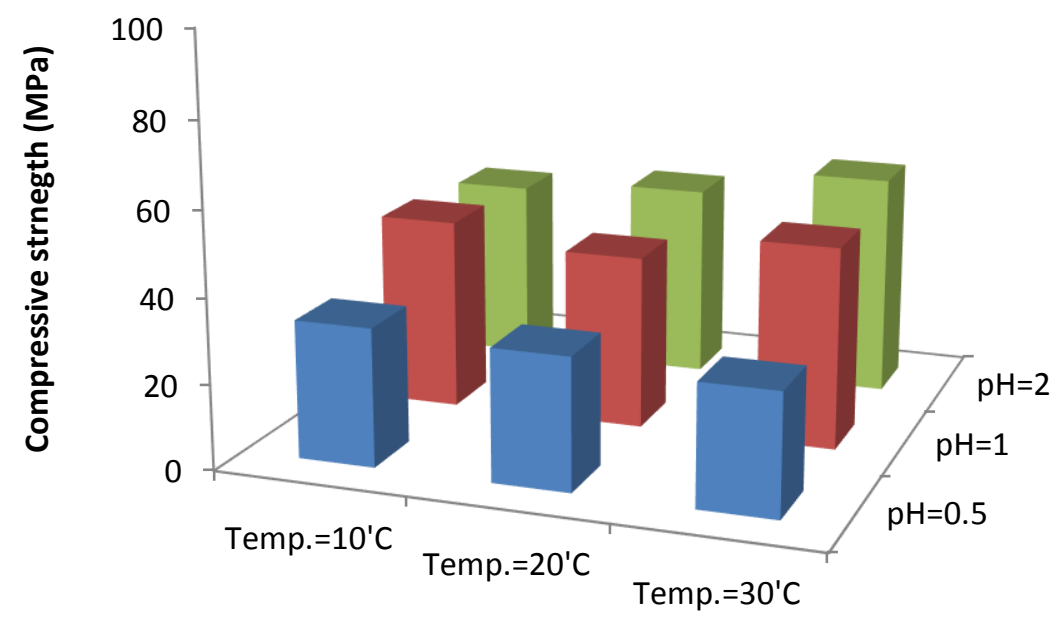

466

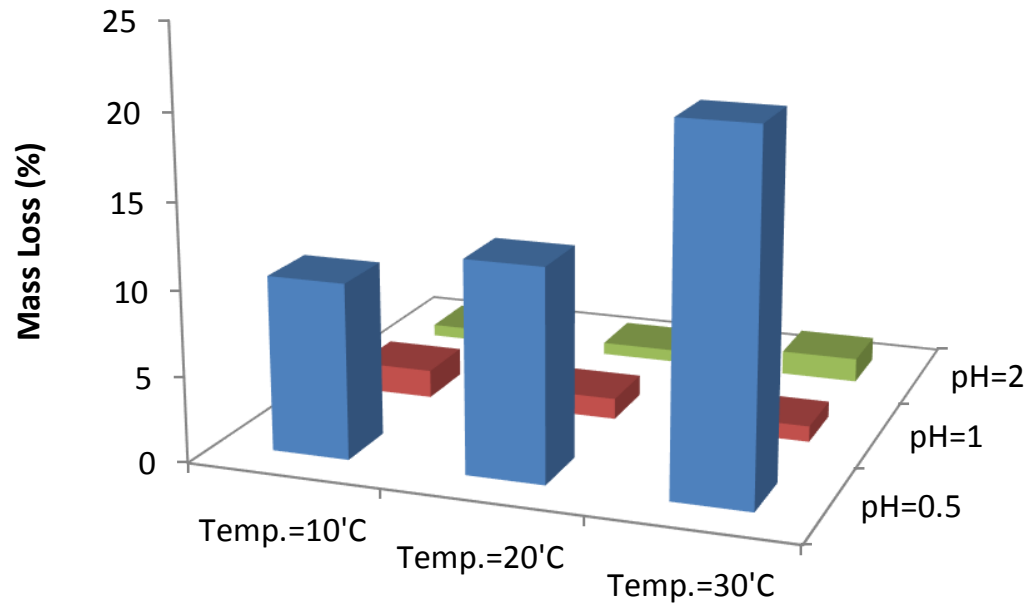

468 Figure 9. Variation in compressive strength and mass loss after 91 days immersion 469 


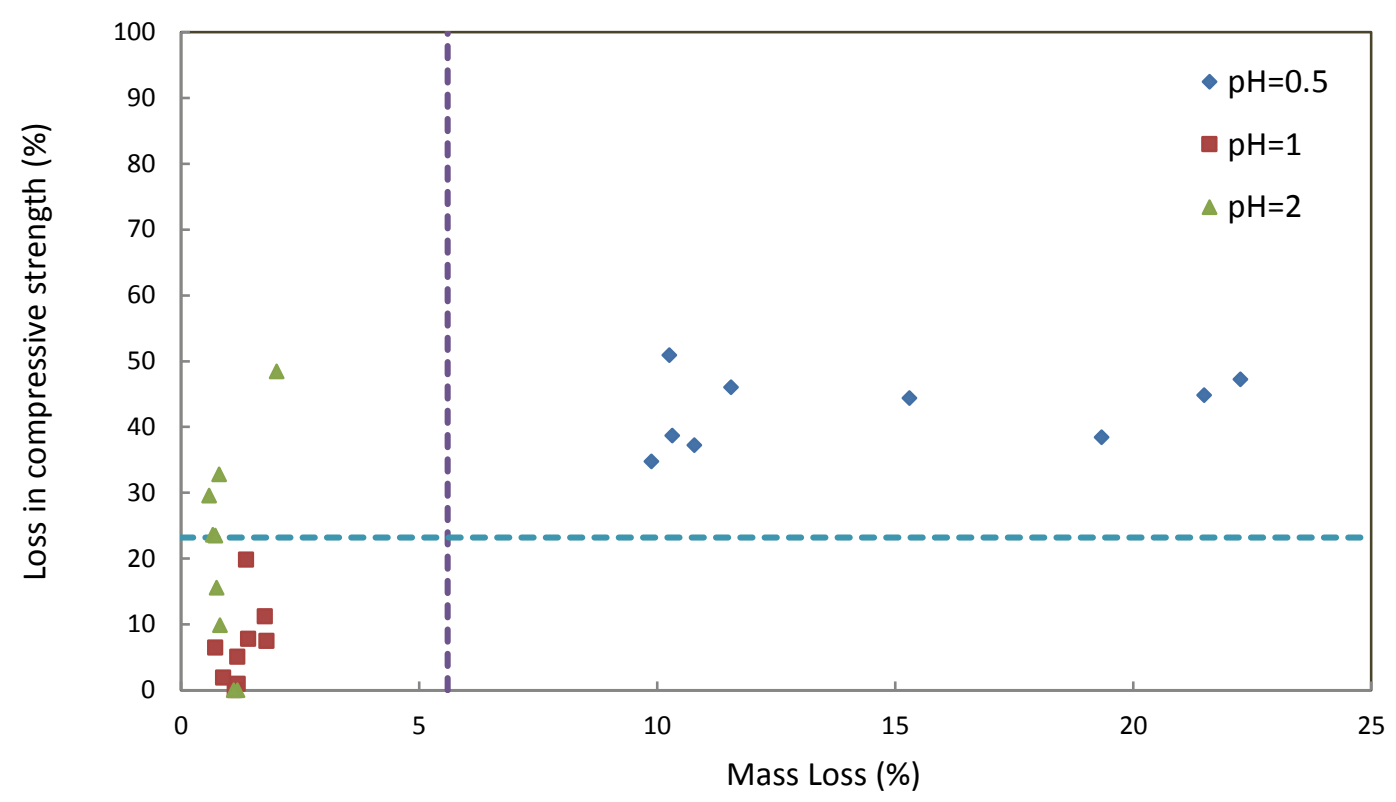

470

471 Figure 10. Relationship between mass loss of concrete specimens and loss in their 472 compressive strength due to 91 days of immersion in sulphuric acid solutions 